\title{
The End of Theorists:
}

The Relevance, Opportunities, and Pitfalls of Theorizing in Sociology Today 


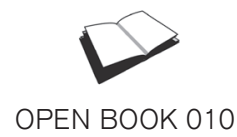

The End of Theorists: The Relevance, Opportunities, and Pitfalls of Theorizing in Sociology Today

Omar Lizardo

Pamphlets for print and screen.

Share, distribute, copy, enjoy.

Authors' words and IP are their own.

(c) (7) (8) 
I decided to make this talk about the current state of theory and the theory field, rather than doing some sort of retrospective on something that I have already done, because this is a topic that is of crucial importance for anybody interested in the future of theory in American sociology. This is also a topic that is especially relevant for those same-generation consociates and younger generation successors who care to self-identify as "theory people." This occasion, I think, presents itself as the perfect opportunity to air out my own sense of where things are at and where things are going. This forum also provides me with a chance to open up a line of discussion with you - that is, the theory people sitting in the crowd.

What I have to say is divided into roughly two parts. First, I want to provide a diagnostic of the state of the theory field in sociology today. This will be essentially an expanded and updated version of some remarks that I gave at the Junior Theorists Symposium a few years ago.

This part of the talk will be mostly bad news. The basic takeaway is that the conditions for doing theory today have changed so dramatically that it is unlikely that the sort of "theory" that self-identified "theory people" will be producing today will bear any resemblance to the sort of thing that was considered theory (and which defined the prototype for the theory category) a generation before. In this respect, the generational divide between theory people today and our predecessors is not only an ideological gap based on changing tastes for theory or theorists but also a real gap based on the material conditions for the production of theory as a cultural object. If you are a theory person under the age of 45 you 
currently live and will live in a different theory world than your predecessors.

In the second part of the talk I will attempt to be a little more positive - but just a little. The takeaway here is that the changing field-level conditions open up both pitfalls and opportunities. The pitfalls come from the natural way in which persons respond to changing conditions. In contrast to the standard approach, in which actors immediately respond to field-level change in quasiadaptive ways, I will argue that the main danger that we face will be the predictable temptation to engage in modes of theory production and consumption that no longer fit the structure of the field. These attempts are bound to fail and may produce a situation in which newcomers into the theory field will be induced to disinvest from the field precisely because their expectations, which are attuned to an earlier state of the field, will be consistently betrayed by it. I think something like that is already beginning to happen.

There are, however, opportunities to change things around, although the task will not be easy. I will identify a couple of strategies that strike me as having the most potential. The first is a move towards institutionalizing a new set of "positions" for the increasingly uprooted theory people floating around in the field. I will propose one model for such a position based on the role that philosophers play in the disciplinary collective known as cognitive science. Here the theorist is a generalist that is both familiar with the nitty-gritty empirical problems of the different fields and who uses a selective, generalist strategy to provide conceptual solutions to those problems. Because the internal sub-disciplinary structure of sociology resembles the disciplinary 
structure of the cognitive science federation, I believe that there is both a demand for and a structural opportunity for the creation of a new theorist position that is adapted to the contemporary conditions of the field. Here history and path dependence are important because the first occupiers of the position are bound to leave a non-negligible imprint on the future definition of the position.

The other productive pathway that I see opening up (and here I have been inspired by the recent work of Richard Swedberg) is a revival of interest in the notion of theorizing as a process and as an acquired skill. My recommendation will be that we should begin to move away from our obsession with theory as a finished product or as canon of works and towards a conception of theorizing as a creative activity. One of the grave dangers that I see today is the continuing survival of an approach to theory that conceives of the theory field as an "aristocracy of theorists" ruling over mere empirical under-laborers. From this perspective, theory is something that is done by a select few who have a special vision; they are only discovered, never made. The problem is that these select few tend to be overwhelmingly white and overwhelmingly male, which has made the theory section look demographically anachronistic in relation to the overall discipline and the more vibrant ASA sections. I will argue that a move towards making the creative part of theorizing explicit can help us move the field towards a democracy of theorists.

Before getting to that, I want to begin by getting clear on the "definitional" issue of what I mean by theory and who is a theorist. 
Gabi Abend wrote a paper in which he distinguished seven different meanings of the word theory. I think seven is a lower bound, and we can spend the next forty years arguing about whether there are seven or twenty "meanings" of theory. The main point is that theory and theorizing is just not a single thing. But this is not just a definitional or "lexicographic" issue, or even an issue of the fundamental polysemy of all meanings; it is a reality pointing to the objective fact that there are multiple modes of doing theory. These modes entail different sets of initial dispositions, different histories of acquisition, and ultimately the mastery of distinct (and possibly conflicting) sets of skills. The theory field is defined by the existence of a symbolic hierarchy among these modes as well as constant contestation among the different modes for the title - which one gets to sit atop the hierarchy.

For that reason, if we want to get a handle on what theory "is" we must distinguish between two ways in which theory presents itself to us. First, there is "theory" as a set of objective "works" and even a "canon" of such works. To paraphrase Simmel, we may refer to this as theory in the mode of "objective culture" or, if you prefer paraphrasing Marx, we may call it "dead theoretical labor." Second, there is theory in the mode of subjective culture, or once again if you prefer Marx, "living theoretical labor." This last is the set of cultured capacities necessary to generate objectified theoretical work.

In each generation, prospective theorists first become proficient at the consumption of dead theoretical labor, so that they may later join the select group of people in charge of producing living theory. While all theory 
producers are theory consumers not all consumers make it to the restricted field of theory production. Playing the "role" of theorist essentially means engaging in the routine exploitation of the cultured capacities for consuming and producing theory.

At any point in time a set of capacities and works may come to occupy a hegemonic position as "the" way to do theory, while other capacities and works are seen as peripheral, insurgent, or secondary. I think I don't have to tell you that it is precisely "the meaning of theory" that is at stake in the theory field at any given time, as was emphasized by Peeter Selg in a recent paper. A newcomer/incumbent dynamic whereby new entrants into the theory field must decide either to reproduce hegemonic modes of doing theory or attempt to go for broke in championing an insurgent mode generates predictable cyclical dynamics of the valuation and devaluation of different modes of doing theory.

For instance, during the late 1970s a certain cadre of theorists could deploy a familiarity with the post-war tradition of logical positivism in the philosophy of science (like the work of Popper, Hempel, Reichenbach and others) in order to establish a new mode of doing theory, which entailed both a "definition" of theory, like the notion of theory as a system of linked propositions that start from first principles and end with the deduction of empirical predictions, and a new mode of doing theory, dubbed "theory construction." Eventually that mode of doing theory was attacked by theorists that drew on post-1960s sensibilities in the philosophy of science (the work of such figures as Lakatos, Feyerabend, Rorty, and others) so that they could develop theory in a post-positivist mode. In this way a largely purist and 
exclusionary sensibility for doing theory was replaced by a more inclusivist approach - one that even made room for a recuperation of the classics as legitimate resources for theorizing (an approach best exemplified in Jeff Alexander's Theoretical Logic in Sociology).

So who is a theorist? Towards the tail end of the Parsonian period, three groups of people began to claim this label: First, there were those that, following Parsons 1.0 (i.e. the Parsons of Structure of Social Action), saw theory as essentially the derivation of creative insights from careful exegesis of the classics; there were others who, following Parsons 2.0 (essentially the Parsons of The Social System), saw theory as the construction of abstract generalizations following some fundamental master-conception of both contemporary and historical societies. Third, there were those who, following something closer to the "Mertonian" route, saw theory as the "codification" of field and subfield specific abstract generalizations in the form of sometimes quasi- and sometimes fully deductive systems. When this Mertonian strain crossbred with the incorporation of Vienna-style logical positivism, we found theorists who viewed themselves as the "theory construction" people that I mentioned before. While not influential in a discipline-wide sense, this group saw themselves as the vanguard of a "scientific" conception of sociological theory. Some of them were even able to gain some nonnegligible influence in certain areas of social psychology, such as the study of group processes.

The point is that there is no a priori answer to the question of who is a theorist and what is theory, since that is precisely what we are always attempting to establish within the theory field. Yet although the 
simplest answer, if formally correct, is the tautological one ("theory is what people who call themselves theorists say it is"), the historical answer is this: for a long time, even after the so-called "crisis" precipitated by the end of functionalism, what theory was in terms of the cultured capacities required to be a theorist, and even in terms of the objectified canon of what was considered theory, remained remarkably uncontested because even through all of the seeming change the basic "doxa" in the theory field went largely unquestioned.

Not only that, even as sociology became increasingly "professionalized" during the 1970s and 1980s the position of theorist and thus the expected career rewards and trajectory that a person who claimed the role was expected to secure became remarkably stable. This would all begin to change during the late 1980s and through the 1990s. This was happening even as new modes of doing theory, like structuralism, post-structuralism, and postmodernism made their presence known. Ideologically, these changes began to be reflected in periodic manifestations of concern as to whether sociology was "pro-science or anti-science," or whether the fragmentation characteristic of empirical work in sociology made any attempt at real theorizing impossible. However, the morphological changes that have led to the contemporary state of the theory field have more mundane - and more consequential - causes. The state of the theory of field today can be characterized by four interlinked dynamics: The deinstitutionalization of the teaching of theory, the devaluation of theoretical work as linked to career trajectories, the slow but steady accumulation of multiple modes of doing theory without a clear structuring principle of organizing the different modes, and the final exhaustion of the European (in 
particular French) tradition of theory. Let me briefly elaborate on each.

The de-institutionalization of the teaching of theory at the graduate level dynamic has been noted before (in particular in a revealing piece by Michele Lamont in Perspectives in the mid-2000s) but its impact is only now beginning to be felt. Most top graduate programs have cut back the required theory class to a single "omnibus" course that attempts the impossible task of going from Montesquieu to Judith Butler in one semester. This goes hand and in hand with the rapid displacement of the graduate seminar as the place where learning happens in top sociology programs. This is coupled with the push to get students out of the seminar and in front of the word-processing program earlier in the grad school career, so that they can realistically finish in 5 to 6 years and have publications to show for it. This dynamic creates a supply-side constraint on who can teach theory. With graduate programs selecting top candidates based on publication records in the top empirical journals, we have a situation in which most people entrusted with the teaching of theory as an objectified set of works may not have the cultured capacities to produce such work. That is, they would not have counted as theorists in a previous state of the field; instead absent a "genuine" theorist, and given that theory now is a low status "hot potato" course that nobody who has any say wants to teach, the teaching of theory comes to be increasingly entrusted to younger faculty (usually assistant professors or young associates) whose work is only relatively theoretical in comparison to other denizens of that department. For instance, said faculty might specialize in the study of culture, institutions, or historical and economic sociology, subfields that are recognized as relatively 
more "theoretical."

With deinstitutionalization, comes devaluation; a theory paper or even a series of papers dedicated to theory have come to be seen as much less valuable than empirically "applied" work (whether qualitative or quantitative). Administrators and high-level decision-makers are under increasing pressure to demonstrate that tenuretrack faculty members produce "useful" research, and by useful they mean the research that gets grants. This means work oriented to technique and the generation of reportable findings rather than conceptual issues. The fact that some modes of doing theory stand at the crossroads of the humanities and the social sciences adds to its woes insofar as the increasingly brazen attack, dismantling, and destitution of the humanities across American universities (especially the public universities) becomes a de facto attack on theory. The emergence of increasingly "rationalized" and quantified measures of the impact or worth of published works means that theory falls even further behind; the impact factors of top theory journals (e.g. Sociological Theory, Theory and Society) are much lower than those of top empirical journals. The increasing heteronomy of university book publishers vis-à-vis the market adds to the problem; theory books are long, wordy and demanding. They cannot be marketed, "Gladwellized" or sensationalized in the same way as empirically oriented books.

With the dissolution of the proper material conditions for the doing of theory comes the partial destructuration of any sort of "hierarchy" of modes of doing theory. While we usually recoil from hierarchy, fields require a working hierarchy to properly function. A de-structured field is an anomic, dysfunctional field. In the good ol' days the 
guidelines were simple, because the field had a more coherent structure, and the sources of theoretical capital were clear. All of the older, consecrated incumbents in the theory field (e.g. Collins, or Alexander, or Turner, etc.) began their careers with some sort of serious engagement with the classics (as defined by Parsons). Then they went on to engage in their own tweaking of the classical tradition, possibly infused with a heavy dose of post-classical influences (e.g. structuralism, post-functionalist sociology, symbolic interactionism, pragmatism, etc.).

Today, things are not so simple. Even though we have better historiographic and exegetical sources on the classics than ever before, work on classical sociology by young theorists is very scarce. The theoretical capital that can be accrued by turning to so-called "contemporary theorists" across the human sciences is equally problematic from an evaluational point of view within sociology, because the contemporary theorists simply lack the consensual field-wide recognition enjoyed by the classics. Since the 1990s, we have seen various theoretical fads come and go, but each has left some cadre of practitioners of that mode of doing theory. This means that today there is a rudderless heterodoxy, with various claimants for the title of preferred mode of doing theory but very little agreement as to the "rules" of the theoretical game. With very little communication across these Islands, the theory field runs the risk of essentially getting stuck on a bad anomic equilibrium.

After de-structuration comes the exhaustion of the source of novel ideas. The Anglo theory field has always been a net importer of theoretical ideas from the FrancoGerman theory field. This arrangement worked out well 
through the 20th century because that meant that players in the Anglo theory field could garner huge reputations via the translation and synthesis of creative theory ideas from the continental field, as Parsons did in the 1930s and Anthony Giddens did in the 1970s, In fact, we can play a game and trace all of what has gone by the name of theory in the Anglo theory field to three generations of European intellectuals: the pre-war "great" generation of the 1890s (Durkheim, Weber, Tonnies, Simmel, Tarde), the interwar generation of Austro-German emigres (Popper, Hempel), and the post-war generation of 1950s French intellectuals associated with structuralism and related "post" intellectual movements (this is Merleau-Ponty, Foucault, Lacan, Barthes, Levi-Strauss, Althusser, Derrida, Deleuze, Baudrillard, and Bourdieu if you are counting). The first gives us classical theory, the second gives us the various theory construction and analytical sociologies (Merton was deeply influenced by the Popperian and logical-positivist traditions) and the third gives us "contemporary theory" (as mediated by such Anglo intermediaries as Giddens). Various contests as to the "meaning of theory" in the American theory of field in the 1980s and 1990s essentially boiled down to avatars of these three traditions wrestling one another for hegemony.

While nobody doubts that the first two traditions of theory are certainly exhausted as living inspirations for contemporary theory work (even though we are living through a renaissance of creative intellectual work on the classics qua classics) we are still living under the illusion that the French structuralist and post-structuralist tradition is an endless fountain of ideas. In fact, a look at standard syllabi for whatever "contemporary theory" courses remain, reveals that the contemporary 
theory canon is essentially built on these structuralist and poststructuralist foundations. But this is quite a bizarre situation, since it ignores the fact that the basic structuralist ideas are now more than 50 years old and that structuralism as a scientific intellectual movement was already exhausted in Paris by the late 1960s (and this was noted by Anthony Giddens in the 1980s).

The rise to stardom of such figures as Bourdieu and Foucault in the Anglo theory field during the 1980s and 1990s was a huge red herring because it gave the impression that the theory field in France was still a vibrant source of ideas (meaning that we could just wait for the next big thing and import his or her ideas) when it was already in full decline. In fact, as revealed by some recent historiography, it is remarkable how exceptional the circumstances that allowed the French generation of the 1950s to engage in the sort of creative theoretical work that begat structuralism were. Precisely because the circumstances were exceptional they were not bound to last and by the beginning of the 1970s the material and social conditions that had led to such an efflorescence of creative work in the French theory field were gone. That also means that no successor to Bourdieu and Foucault is going to materialize any time soon to save the day.

Yet, a quick scan of some of the best theory work produced by some of our best theory people, or even some of the theory papers presented at the Junior Theorist Symposium reveals how important this line of French theorists for defining what usually gets called "contemporary theory" and how much of an idea resource it is. The fact that a 50 year old line of thinking gets called contemporary; the fact that we have developed the equivalent of a substance dependence 
on this line of thinking; even the fact that today we are beginning to treat some of these theorists in the same "exegetical" way that we treat Marx or Weber speaks for how dire of a situation the theory field is in in terms of the net generation of creative ideas.

\section{And now, for the "good news."}

So what do? First it is important to get clear on what not to do. One tempting strategy is to attempt to re-establish the hegemony of some preferred mode of doing theory over the others. In essence this is an attempt to reconstruct a coherent hierarchy of modes of doing theory in order to reinstate a sense of order, security, and predictability to the theory field. This seems to be the implicit strategy behind such scientific-intellectual movements as Critical Realism or Analytical Sociology. Proponents of this solution work from their own the diagnosis of what they see as the main problem in the theory field today: its generally anomic, fragmented, rudderless, nature. However, their solution is misguided since there is very little practical or ideological chance that the arrow of time can be turned backward. The reality is that as it has evolved, the theory field in American sociology has come to acquire a multicentric structure that would be very hard to reconfigure into a hegemonic one. These movements throw the baby of the pluralistic potential of the current theory field out with the bathwater of fragmentation and cacophony. I believe that theoretical creativity under the current state of the field requires what Don Levine has referred to as a "dialogical" respect for a multiplicity of voices and theoretical traditions. In this respect, the re-establishment of a consensual theoretical canon or the attempt to unify theoretical work in sociology under a single banner strike me as 
strategies that are both unfeasible and undesirable.

Another danger, as I mentioned, is simply to stick to one's guns and just attempt to deploy intellectual strategies that worked well in the past (at least for the purposes of establishing a coherent position). For instance, this may include a heavy investment in the classics, attempts at conceptual unification of sociology around grand metaconceptions of science (whether good old fashioned positivist, post-positivist, realist, or constructivist), attempts to deploy a single grand set of mechanisms or heuristics (e.g. micro-foundations, micro-translation, actor-network theory, field theory, interpretivism). These will not work. Neither will a complete flight from theory as traditionally conceived and towards the seeming empiricist panacea presented by mathematical, simulation-based, or computational models of social life. These strategies are dangerous precisely because whoever deploys them is bound to anticipate rewards and possibilities that the field can no longer deliver. Betrayed, actors that enact these strategies are likely to dis-invest from the field, which would also mean a net loss of theoretical talent and creativity (or a "brain drain" of potentially creative theory people to other subdisciplinary endeavors).

I believe that any attempt to re-establish a semblance of order and coherence to the theory field must base its strategy on a correct diagnosis of the problem. The problem is not necessarily the proliferation of different modes of doing theory but a mismatch between the increasingly vanishing position of theorist in the wider field of sociology and the relative oversupply of people endowed with the cultured capacities to do theory today. In essence, people who invest in theory no longer 
have any guarantee of coherent trajectories in the field. With the overall field increasingly likely to dis-invest in the theory field, it is only a matter of time before newcomers readjust and begin to disinvest in theory (which is something that is already happening at the elite level). So what is required is a reconfiguration of the theorist position so that it can again play a proper role in the larger sociological field. Essentially we need to reincorporate the theorist as a functioning member of the sociological collective.

What can theorists do that others cannot? My argument is that the comparative advantage of the theorist is her penchant for generalism and her capacity to resist the forces of hyper-specialization. A theorist today is an "omnivore" consumer of sociological sub-areas, and thus an actor well-positioned to detect, diagnose, and propose incipient solutions to common conceptual and substantive issues across seemingly disparate domains of inquiry. This type of work is not to be confused by what used to go by the name of "meta-theory" in the 1980s and 1990s. That was essentially a largely selfreferential discourse about theory. Instead, what I refer to is the capacity to read widely across subfields and to link substantive problems across analytic levels and across substantive domains.

It turns out that there is already a working model for such a position and it exists in the interdisciplinary federation known as cognitive science. There philosophers play such a role and occupy such a functional position. In contrast to the old picture of the philosopher as a provider of normative guidelines as to how to conduct scientific inquiry or as a legislator as to the proper use of language and concepts, what 
we see in cognitive science is philosophers becoming disciplinary omnivores and reading across a wide swaths of subfields including linguistics, psychology, neuroscience, anthropology, robotics, and so on in order to identify common problems across different areas and to provide theoretical solutions that travel well across disciplines. Some successful examples of "theorists" in this sense include such people as Andy Clark, Evan Thompson, and Alva Noe, among others.

Note that my argument goes beyond the observation that this is an ideological possibility; I would argue that the objective conditions in the sociology field are ripe for the creation of such a position for the theorist. As American sociology has evolved in the last three decades, it has acquired a federation-like internal structure that is structurally analogous to that of cognitive science. There is thus a structurally unmet demand for subdisciplinary omnivores endowed with the cultured capacities to recognize relatively abstract argument types, crosssubfield mechanisms, cross-domain processes, and even what John Martin has referred to as "thought chunks" that re-appear across areas of inquiry. In my view relatively recent newcomers into the theory field tend to be well-equipped to engage in this sort of work, and there are examples of people that are doing this type of internally integrative theorizing: I refer to such people as Iddo Tavory, Isaac Reed, Gabe Ignatow, Gabi Abend, and others, all of whom apply a clearly identifiable set of philosophical sensibilities for the identification of argumentative forms with a capacity to integrate across empirical domains. In fact, they might be (and I hope they are) the sort of position pioneers that might reconfigure the theorist position in modern American sociology and provide their own imprint to it. 
The second thing that I think we need to start doing is moving away from a conception of theory as finished products and move towards a conception of theory as a set of generative skills geared to the creative production of theory. This is what Richard Swedberg has called the move from theory to theorizing. This move is particularly crucial at this juncture precisely because of my remarks above regarding the exhaustion of theoretical sources of new theoretical ideas. Theorists in the Anglo theory field need to start moving away from being clever consumers and adapters of European theoretical ideas. If we are going to get innovation at the level of ideas in the theory field, we need to stop waiting for the next French big thing and start producing our own.

The problem of course is that we have no clue as to how theorizing is done. And the reason for this is that received pictures from the "analytical" and "continental" theory tradition make this process into a mystery. In the analytical view, the irrationalism of theoretical discovery is an embarrassment that must be dealt with by focusing our efforts on objectively justifiable procedures in the so-called context of justification. In the continental perspective the irrationalism of theoretical discovery is a virtue to be celebrated, but one that must be forever protected from any sort of explicit dissection. We need to move beyond the limitations of both of these traditions and join the move towards theorizing. This is the one of the only hopes we have to actually get some good home-grown theory in the contemporary theory field.

The new theorizing movement shares with practicebased and pragmatist sociologies a rationalistic commitment to viewing theory as a form of skill. This 
cultured capacity to produce theory is one that usually lives in the tacit domain, but which also has the potential to be subjected to systematic analysis. This analysis can then lead to the potential to transmit this knowledge cross-generationally via traditional pedagogical techniques. This is important, because explicit allegiance to a romantic irrationalist model of the creative theorist leads to an anti-democratic conception of theorizing as a non-transferable aptitude, and of the theorist as a select creative genius who just happens to possess that aptitude.

As Swedberg and other analysts behind the new theorizing movement (such as Karin Knorr-Cetina and Diane Vaughan) propose, one way to move towards the systematic analysis of the theorizing process is by borrowing tools from the disciplinary fields that are in fact in charge of the systematic study of cognition. These include in addition to cognitive psychology and the psychology of reasoning such fields as cognitive linguistics, the cognitive study of analogical thinking, and cognitive semantics. The only way to understand theorizing is to understand how the mind generates meaning and for that we need the multi-disciplinary resources of those fields in charge of doing just that.

If the traditional understanding (whether analytical or continental) of theoretical cognition has been generally anti-naturalist, a move towards a cognitive understanding of theorizing can be understood as part of a larger movement towards naturalism in the study of culture and cognition. In this way, the new theorizing movement can best be understood as an attempt to develop a naturalistic understanding of theoretical cognition in social theory. This approach links nicely with recent moves towards both cognitive science and 
naturalism in the philosophy and history of science.

To sum up, the theory field today faces daunting challenges. It is beset by a series of crises coming from the objective conditions of knowledge production, the changing nature of higher education, and the historical proliferation of modes of theorizing that produce an increasingly hard to navigate structure. This poses problems for the reproduction of the field as both the position of the theorist and the functions of theory begin to be called into question. But as I hope to have shown, this crisis is also an opportunity for reconstruction and renewal, one that if taken up in the right way can result in the production of bigger and better theory, which will hopefully be of some use for the forthcoming generation of successors in the theory field. 

This essay is drawn from the Lewis Coser Memorial Lecture, delivered August 17th 2014 in San Francisco. 


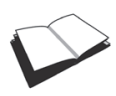

